\title{
Designing an Educational Aid Tool to Learning Waste Separation for 5-7 Years Old Children
}

\author{
Nasser Kolaini Mamghani, Iran University of Science and Technology, Iran \\ Sara Mostowfi, Iran University of Science and Technology, Iran \\ Mehdi Khorram, Iran University of Science and Technology, Tehran, Iran
}

\begin{abstract}
Due to a progressive deterioration of our planet and its resources, environmental education has become crucial and children should be trained to understand environmental issues at an early age so they can cultivate positive change in the future. This study combines research in child development \& educational strategies with environmentally related issues into a game that promotes active learning. Data for the study is gathered in a qualitative manner, introducing child participants to existing environmental games and collecting their feedback into graphic organizers. For this study 15 children (5-7) years old were selected for participated in design process. Most methods which were selected for surveying were based on children psychology, and characteristic. At the end a prototype of an environmental education game that combines various styles of play will then be designed based on the gathered data. The game aims to explore concepts, scenarios, and strategies of environmental preservation, encouraging children to become active participants in preserving the planet and promoting environmentally responsible behavior.
\end{abstract}

Keywords: play, environmental education, active learning, design of education game 


\section{Introduction}

The twenty first century brought new challenges to teachers. They have to compete harder for students' attention against many factors, such as personal interests, video games, surfing the Web, social media, cell phones apps, text-messaging, and so forth. Students have always faced distractions and time-wasters, but the tablets and cell phones, and the constant stream of stimuli they offer pose a profound new challenge to focusing and learning. (1) Children learn through play, explore, communicate through social interaction and duplication of each other, they also learn new skills and cooperation with others. However, it has been observed that school computers are used mainly for personal training. Also, most educational media for children's social aspects of learning and culture do not report such content. New media offers limited opportunities for creative interaction. (2) Today's research area is more focus on the effort to create products that can entertain children like TV. In order to successfully engage children in play, we need to understand the kind of interaction we have made tangible for children of all ages. (3) For example, children aged 12-18 months has begun to experiment with objects and is able to make marks on paper simply, while a 4-year-old children is fully able to identify different types of objects and words and significantly more physically active. Although every child, know how to use simple tools. In this way, we are able to predict the specific interactions in the game that will be according to the average functionality of all ages. (2) Furthermore, the way information is presented to children, influences both their initial understanding of the material and its future retention. Traditional teaching methods involving "mechanically follow[ing] a set of steps or read[ing] and hear[ing] about things learned and done by others" are not as effective a learning tool, as active or inquiry-based systems of education (Elementary Science, 1996, p.A2). Furthermore, the process of playing an educational game supports the understanding of new ideas and theories, in addition to conventional classroom-based methods of instruction. Information acquisition and anticipated retention can be significantly improved if the learning approach is dynamic and enjoyable. (5)

\section{Learning Style:}

All of us do not learn in one way. We tend to indicate the ways, which we are more comfortable and set others aside. It is important that we know our taste of learning styles:

- use Learning techniques that is compatible with our special training which we have learned.

- improve our learning methods in areas that we are weaker. 


\section{Labeling:}

Not giving any explanation, "the same thing is certain and that is" like: this is an orange.

\section{Naming:}

Give Unique information "this is something that is" like: orange is in market.

\section{Linking:}

Pair joined the beliefs, such as: the oranges grows on tree.

\section{Determine the general characteristics:}

Such as similarities, like: orange has round shape and core.

\section{Concept determination on the basis of belonging to a class:}

Knowing the name of the class, Such as the orange fruit is edible. Determined on the basis of belonging to a pattern like: orange is Edible fruits such as oranges / plant / organism.

\section{Setting concepts through association with other patterns:}

Determine similarities, differences compared to other categories, for example, orange in terms of linguistics, mathematics, science, history, geography, economics and other patterns has other meaning.

Due to a better understanding of concepts, especially the concept of the environment, the most basic steps will be explain or describe by the parent or coach that is the scientific process.

The best way for conveying information to children of different levels, is: determining the general features, link and description through word displaying.

\section{Active learning}

Active learning is based on the belief that ALL children can learn. The guiding principle behind this theory is that our job as parents and educators is to create environments or situations that encourage active exploration, without interference from an adult. This means that we are not guiding the child's hands or telling the child what to do. Instead we encourage the child to be an active participant in his or her own learning by creating spaces and presenting materials that are interesting and safe to explore. In order to be most effective, the environment should be responsive, in other words something should happen when a child moves or bangs something. (4444) Ludic activity is proven to encourage and enhance information retention (Heinich, Molenda, Russel, \& Smaldino, 1996), as it provides the player with an opportunity to forget about the act of learning and focus on the act of playing (Peisach, Hardeman, 1985). On a psychological level, information is better perceived and 
later retained if the educational process involves eustress, or the "positive feelings of enjoyment and excitement that one experiences when engaging with something new and different" (Parry, Gregory, 1998, p. 12) in a non-stressful, non-threatening learning environment. Such an environment of eustress can be created if the learner gains their knowledge through the process of play. Consequently, an active engagement with the proceedings of an educational game ensures that the player can learn both from their participation and their observation of others. A game exploring concepts, scenarios, and strategies of environmental preservation can encourage and empower children to become active participants in preserving the planet and promoting environmentally responsible behavior as they move through life.(5)

\section{Methodology}

The purpose of this study was to develop an understanding of the design and organization of important factors that, it's effective in partnership with children. Therefore, the methodology for the development of the study followed by an iterative process of analysis, problem definition and assessment of the research contribution

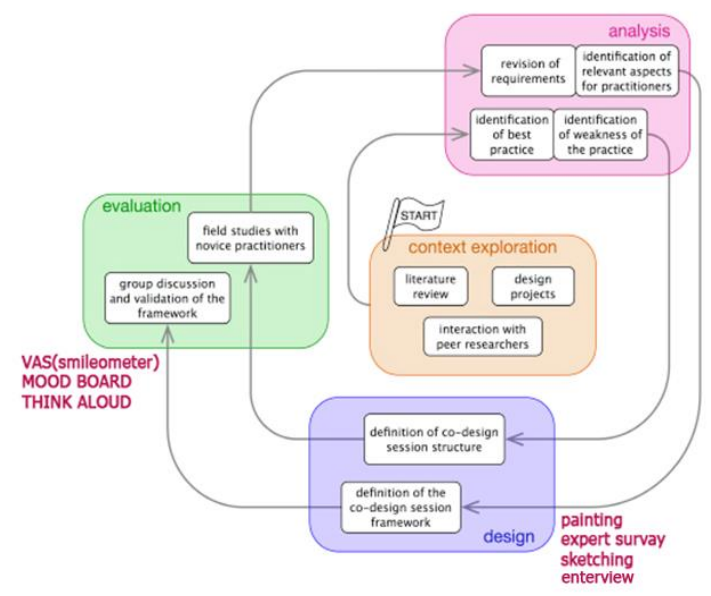

Figure (1):research methodology

\section{User group}

The target group of the project are pre-school 4-6 years old children who are physically and mentally healthy and normal child. The project is for both boys and girls. According to children's developing ability to read, focus, their abstract logical thinking is growing (Markopoulos and Bekker, 2002). First of all, the children in the selected age group should be able to participate in the evaluation of observation. So as a forced choice between four and 
six years, we limit our children. In the following, some view of the children's characteristics between four and six years old, is described:

\section{Hanna, Risden \& Alexander}

In its guidelines for usability testing with children Hanna, Risden, and Alexander (1997) provide three age groups: 2 to 5 years, 6 to 10 years and 11 to 14 years. Children between four and eight years are the youngest average group. Some more detailed characteristics of this age group, according to Hanna, Risden, and Alexander (1997) are:

- 2 to 5 years: focus on preschoolers are somewhat low. In addition, their motivation to please the adults and their ability to adapt to an unfamiliar environment and new people may change from one moment to the next.

They are unpredictable. Therefore, this age group are more extensive compatibility testing user.

- 6 to 10 years: Children in this age group attend school. So they can do things successfully and follow directions from adults. They respond to questions

And trying to experience new things, and they are very concerned about the observed fact of the computer game. Smallest children in this age group (6 and 7) may be a bit shy. (6)

For this project following methods were done through the design process to knowing user better.

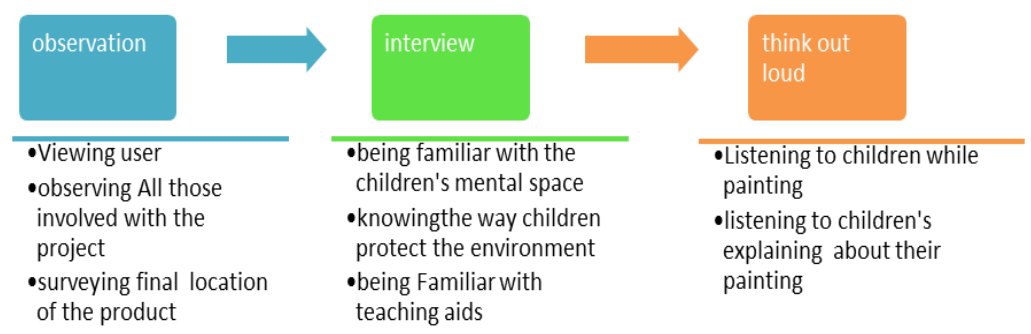

Figure (2): user group study

\section{Observation}

Viewing everything, not only the people or the products but also places and rules. 


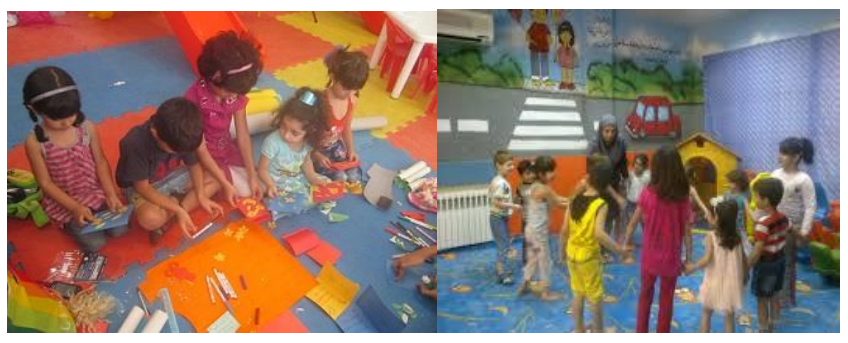

Figure (3):user observation

\section{Interview with Children}

In order to achieve the children's attitude to the environment and knowing their thinking and understanding of the environment. The interview was used. About 30 children 4-6 years old answered these questions:

What is the environment? How do you keep your environment? How can you protect your environment?

Then we asked children to draw painting about environment protection.

Findings indicate that:

-Children environment is limited to the environment in which they live.

-In order to environment protection more children point out: the separation of waste, using public transportation instead of individual vehicles, plant trees and so forth.

\section{Thinking Out Loud}

We want children to draw picture about environmental protection. Then children were asked to explain about each of their painting. This method is widely used in the industry. In this case tested users will be asked to talk about what they think out loud. Findings indicate that:

-The environment can be kept clean by waste separation.

-don't Throwing out your mouth water when you're walking.

-Making place for birds

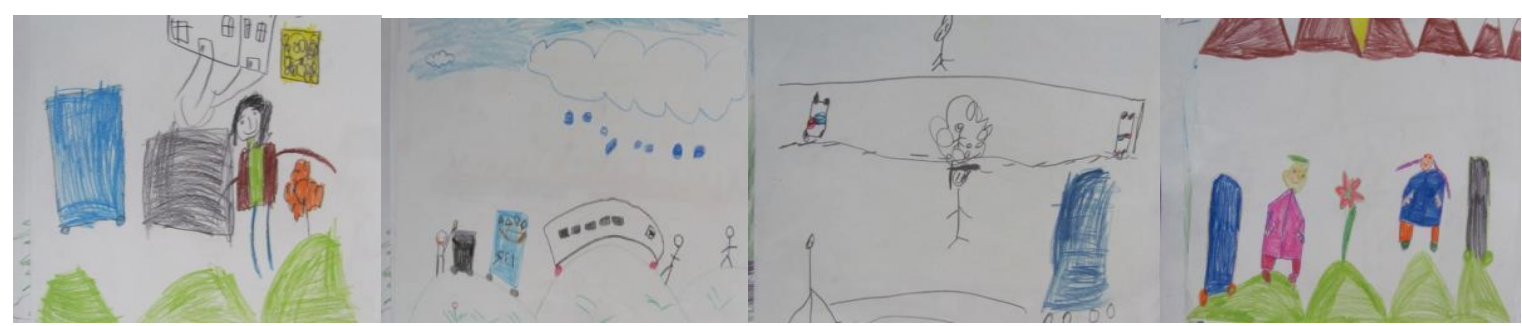

Figure (4): children' painting samples 


\section{Evaluation of the Project}

For designing the play space several sketches were evaluated, first we chose between several sketches which some of them are shown in figure (5)

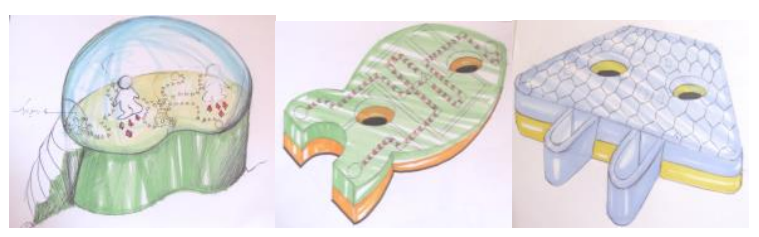

Figure (5): sketching

After that the idea which gained high scores by teacher and families. We made 3D model from them for being evaluated by children.

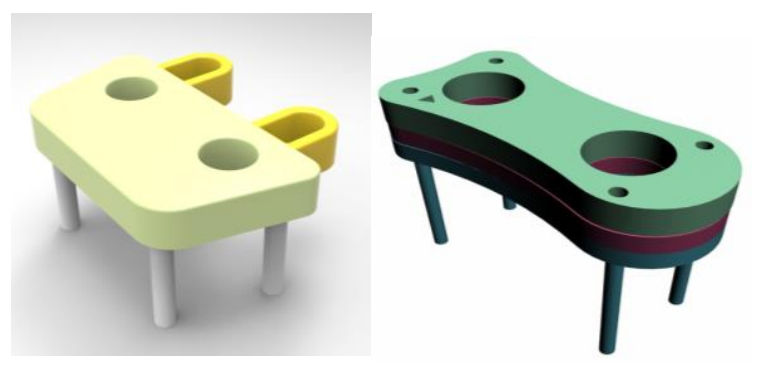

Figure (6): 3D modelling

\section{A survey of Children}

\section{Mood Board by Users}

Mood Board is a set of visual images (e.g. photos, samples of materials) that are collected. This enables designers to communicate and express themselves beyond the limits of the language. Designers can use this tool to communicate subtle and abstract feelings such as happiness, sadness, and comfortable. Pictures can be found in magazines and online resources. In a recent study mood board was carry out by children between 4-6 age, user sample were $(\mathrm{N}=15)$, during the 3 hour participatory workshop. 


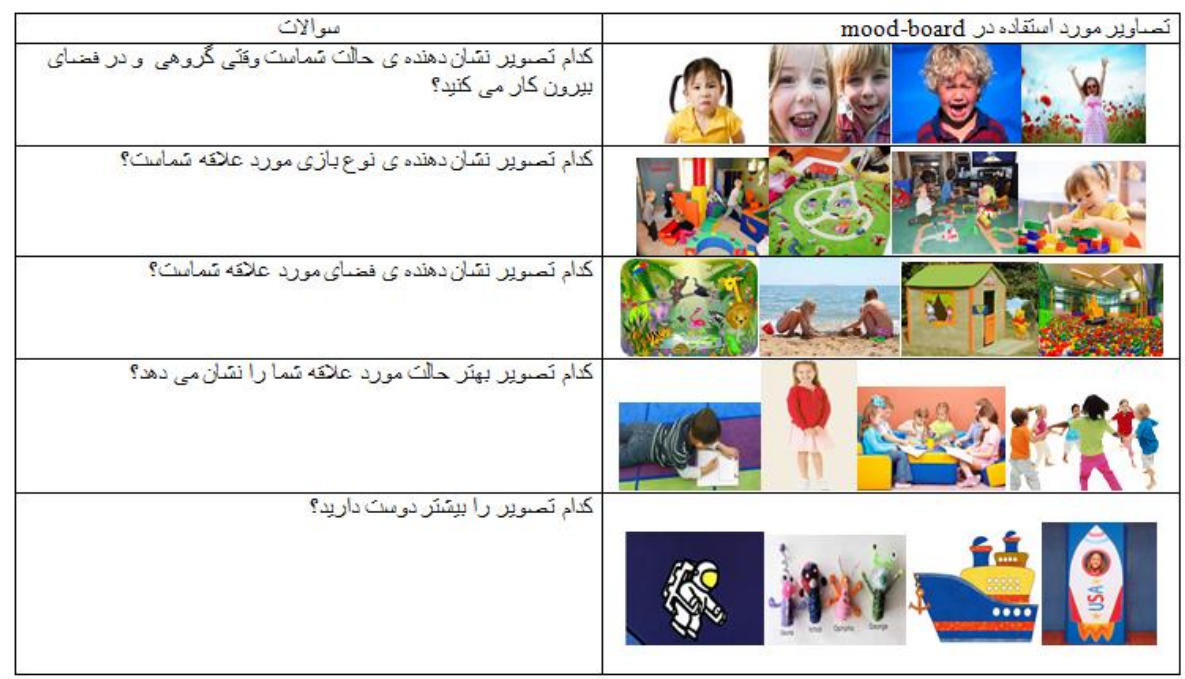

Figure (7): mood board samples

\section{The Results of the Evaluation Board Mode}

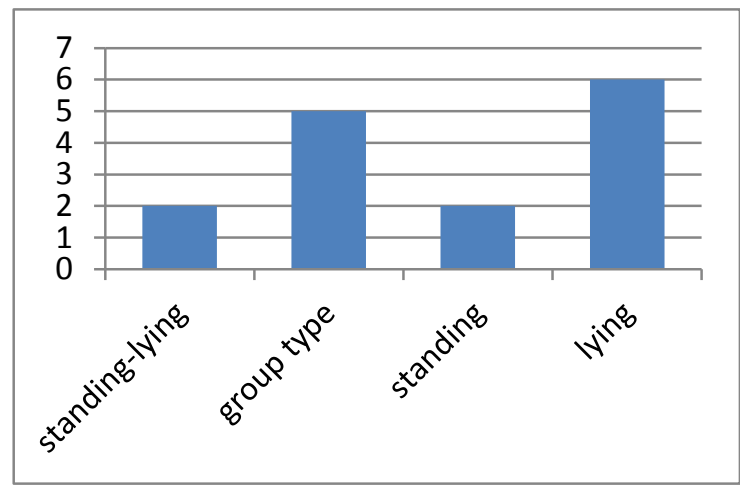

Chart (1): Question 1(which picture show your favorite position?)

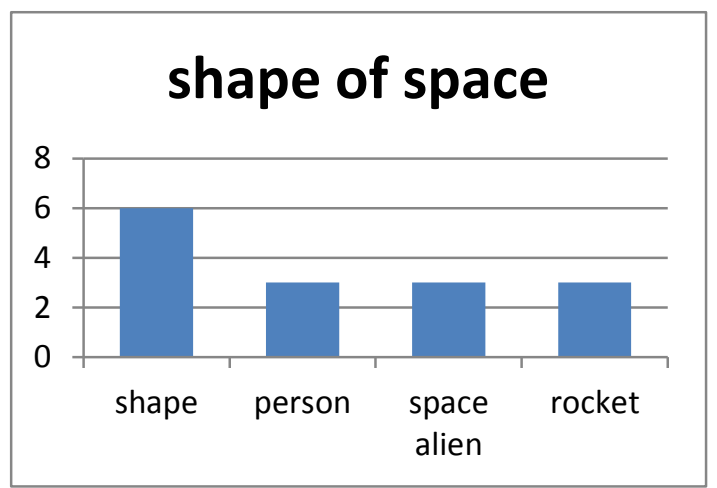

Chart (2): Question 2(which picture do you like?) 


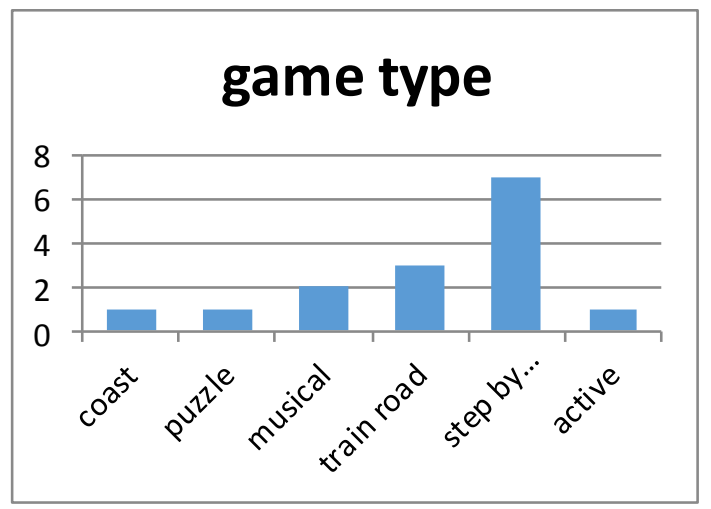

Chart (3): Question 3(which game do you prefer?)

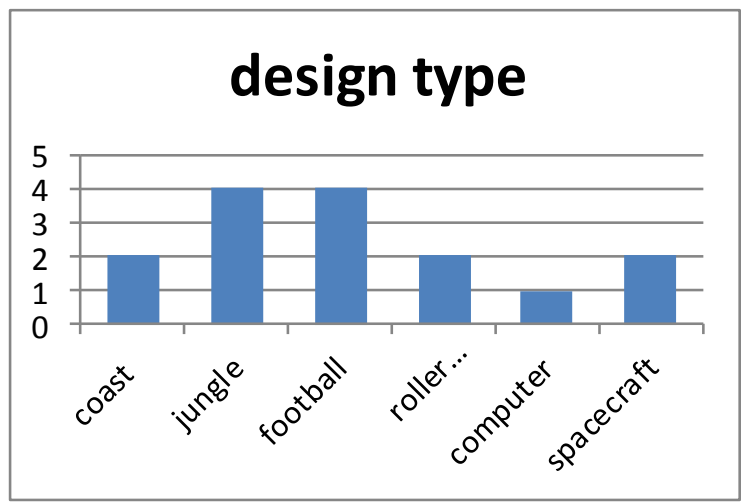

Chart (4): Question 4 (which space or picture do you prefer?)

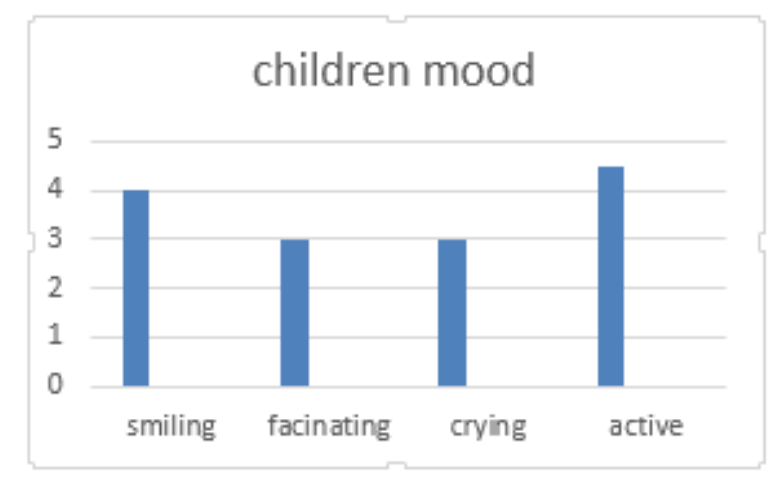

Chart (5): which is your mood when playing in group?

According to results ship shape table was chosen, after that we design two types of game and evaluate it by 10 children with smileymeter questionnaire: 

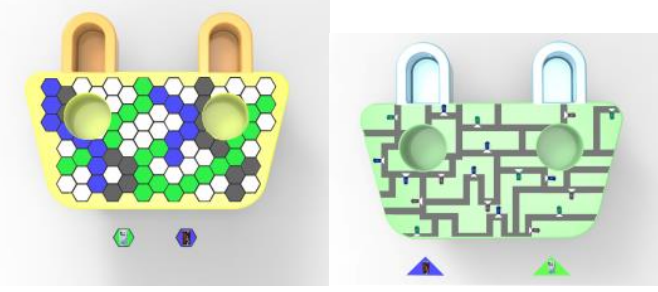

Figure (8):games sample

In the first step: the child was asked to play (A).

In the second step: Then child was given a questionnaire that was designed by Smileymeter and he was asked to answer the following questions:

How much was the game interesting?
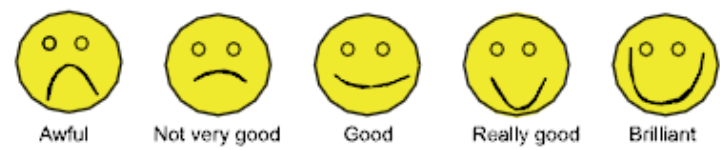

Figure (9): smileymeter

A VAS uses pictorial representations that children use to identify their feelings or opinions. This approach has been adopted as an alternative to the traditional open-ended and closed question formats although some researchers suggest that VAS can only be used with children aged around seven and over .Studies in Child Computer Interaction have shown them to be useful for younger children, but have also noted that when these scales are used to elicit opinions about software or hardware products, younger children are inclined to almost always indicate the highest score on the scale.

Table 1: Mean Scores and Standard Deviation for Smileyomete

\begin{tabular}{|l|l|l|l|l|}
\hline \multicolumn{2}{|l|}{ after } & \multicolumn{2}{|l|}{ before } & \\
\hline SD & mean & SD & mean & \\
\hline 0.728 & 4.3 & 0.774 & 4 & Game B \\
\hline 0.781 & 3.7 & 0.663 & 4.4 & Game A \\
\hline
\end{tabular}

for game (B) the two-tailed $\mathrm{P}$ value equals 0.3837 by conventional criteria, this difference is considered to be not statistically significant. 
For game (A) the two-tailed $\mathrm{P}$ value equals 0.0444 By conventional criteria, this difference is considered to be statistically significant.

In The third step: the child was asked to play (B).

In the fourth stage the child was given a questionnaire designed by Smileymeter and he was asked to rate the attractiveness of its rating.

In the fifth part, the children were asked to choose one of the two games according to their choice. And to answer questions related to this section:

-game (A) vs. game (B) is easier to place the waste in a its place

-game (B) vs. game (A) is more educational and intellectual.

In the sixth stage after the children have answered questions. Children are referred to without the prior award was presented at the chocolate and so on. Encourage the child to continue playing.

\section{Seventh Step:}

At this point, it was suggested that the child is free to select one of the two games that was more educational for him.

With regard to the collection and presentation of children's evaluation, game (A) was elected as the game. So we build its 3D model too.

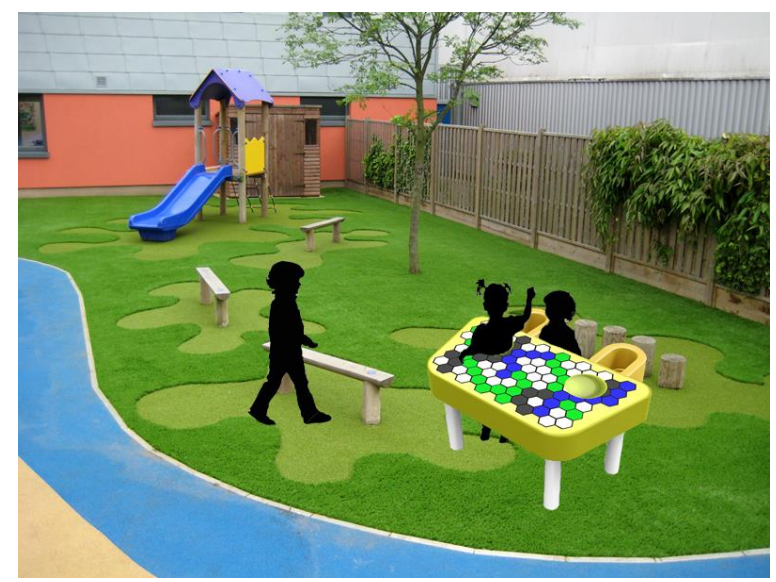

Figure (10):final idea 


\section{References}

"Designing Tangible Interfaces for Children's Collaboration", Diana Africano, Kent Lindbergh, Sara Berg, Peter Lundholm, Fredrik Nilbrink, Anna Persson, Interaction Design Lab, Umeå Institute of Design, Umeå University, CHI 2004, April 24-29, 2004, Vienna, Austria.

"Beyond the Screen: Designing Immersive Collaborative Experiences for Children Through Digital and Physical Interaction", Julia Frederking (Designer), Michael Cruz (Designer), Mark Baskinger, Kees Overbeeke ( Advisor - Carnegie Mellon University)

"Physical Programming: Designing Tools for Children to Create Physical Interactive Environments", Jaime Montemayor, Allison Druin, Allison Farber, Sante Simms, Wayne Churaman, Allison D’Amour, Human-Computer Interaction Lab, Institute for Advanced Computer Studies, University of Maryland, College Park, MD 20742 USA monte@cs.umd.edu, allisond@umiacs.umd.edu

"Designing with Children:Reflections on Effective Involvement of Children in the Interaction Design Process", Emanuela Mazzone, A thesis submitted in partial fulfilment for the requirements of the degree of Doctor of Philosophy, University of Central Lancashire, 2012.

"Understanding Your Users A Practical Guide to User Requirements Methods, Tools, and Techniques",Catherine Courage and Kathy Baxter, Elsevier, 2005.

"Usability of Pictorial Toy Assembly Instructions for Young Children", Cortney V. Martin, Dissertation submitted to the Faculty of the Virginia Polytechnic Institute and State University in partial fulfillment of the requirements for the degree of Doctor of Philosophy in Industrial and Systems Engineering, Blacksburg, Virginia, February 7, 2007.

"Measuring product liking in preschool children: An evaluation of the Smileyometer and This or That methods", Zaman, Bieke, Abeele, Vero Vanden and Grooff, Dirk De, International Journal of Child-Computer Interaction, (2013) 61-70 